\title{
Corrigendum: B cell-helper neutrophils stimulate the diversification and production of immunoglobulin in the marginal zone of the spleen
}

Irene Puga, Montserrat Cols, Carolina M Barra, Bing He, Linda Cassis, Maurizio Gentile, Laura Comerma, Alejo Chorny, Meimei Shan, Weifeng Xu, Giuliana Magri, Daniel M Knowles, Wayne Tam, April Chiu, James B Bussel, Sergi Serrano, José Antonio Lorente, Beatriz Bellosillo, Josep Lloreta, Nuria Juanpere, Francesc Alameda, Teresa Baró, Cristina Díaz de Heredia, Núria Torán, Albert Català, Montserrat Torrebadell, Claudia Fortuny, Victoria Cusí, Carmen Carreras, George A Diaz, J Magarian Blander, Claire-Michèle Farber, Guido Silvestri, Charlotte Cunningham-Rundles, Michaela Calvillo, Carlo Dufour, Lucia Dora Notarangelo, Vassilios Lougaris, Alessandro Plebani, Jean-Laurent Casanova, Stephanie C Ganal, Andreas Diefenbach, Juan Ignacio Aróstegui, Manel Juan, Jordi Yagüe, Nizar Mahlaoui, Jean Donadieu, Kang Chen \& Andrea Cerutti

Nat. Immunol. 13, 170-180 (2012); published online 25 December 2011; corrected after print 12 July 2013

In the version of this article initially published, the second affiliation for Stephanie C. Ganal is missing. This author is also affiliated with the Spemann Graduate School of Biology and Medicine, Freiburg, Germany. The error has been corrected in the HTML and PDF versions of the article.

Corrigendum: Signaling by Fyn-ADAP via the Carma1-Bcl-10-MAP3K7 signalosome exclusively regulates inflammatory cytokine production in NK cells

Kamalakannan Rajasekaran, Pawan Kumar, Kristina M Schuldt, Erik J Peterson, Bart Vanhaesebroeck, Vishva Dixit, Monica S Thakar \& Subramaniam Malarkannan

Nat. Immunol.; doi:10.1038/ni2708; corrected online 23 September 2013

In the version of this article initially published online, the affiliation of author Bart Vanhaesebroeck was incorrect. The correct affiliation is as follows: Center for Cell Signaling, Barts Cancer Institute, Queen Mary University of London, London, UK. The error has been corrected for the print, PDF and HTML versions of this article.

\section{Erratum: Matching cellular dimensions with molecular sizes}

Michael Reth

Nat. Immunol. 14, 765-767 (2013)

In the version of this article originally posted online, the units in the text referring to Figure 1a were incorrect. The correct unit is " $\mu$ " and the correct text is " the receptor depicted would measure about $3 \mu \mathrm{m}$, compared with a resting B lymphocyte, with an average diameter of about $7 \mu \mathrm{m}$." The error has been corrected in this file as of 22 August 2013.

\section{Erratum: The role of the immune system in governing host-microbe interactions in the intestine}

Eric M Brown, Manish Sadarangani \& B Brett Finlay

Nat. Immunol. 14, 660-667 (2013); published online 18 June 2013; corrected after print 20 September 2013

In the version of this article initially published, a label was missing from Figure 2. The lymphoid structure in the large intestine should be labeled 'Isolated lymphoid follicle'. The error has been corrected in the HTML and PDF versions of the article. 